\title{
A!
}

This is an electronic reprint of the original article.

This reprint may differ from the original in pagination and typographic detail.

Lavikka, Rita; Smeds, Riitta; Jaatinen, Miia

\section{A process for building inter-organizational contextual ambidexterity}

Published in:

BUSINESS PROCESS MANAGEMENT JOURNAL

DOI:

10.1108/BPMJ-12-2013-0153

Published: 01/01/2015

Document Version

Peer reviewed version

Please cite the original version:

Lavikka, R., Smeds, R., \& Jaatinen, M. (2015). A process for building inter-organizational contextual ambidexterity. BUSINESS PROCESS MANAGEMENT JOURNAL, 21(5), 1140. https://doi.org/10.1108/BPMJ12-2013-0153

This material is protected by copyright and other intellectual property rights, and duplication or sale of all or part of any of the repository collections is not permitted, except that material may be duplicated by you for your research use or educational purposes in electronic or print form. You must obtain permission for any other use. Electronic or print copies may not be offered, whether for sale or otherwise to anyone who is not an authorised user. 


\section{A process for building inter-organizational contextual ambidexterity}

\section{Author Details}

Author 1 Name: Rita Lavikka

Department: Industrial Engineering and Management

University/Institution: Aalto University, School of Science

Town/City: Espoo

Country: Finland

\section{Author 2 Name: Riitta Smeds}

Department: Industrial Engineering and Management

University/Institution: Aalto University, School of Science

Town/City: Espoo

Country: Finland

Author 3 Name: Miia Jaatinen

Department: Industrial Engineering and Management

University/Institution: Aalto University, School of Science

Town/City: Espoo

Country: Finland

Corresponding author: Rita Lavikka

Corresponding Author's Email: rita.lavikka@aalto.fi

\section{Structured Abstract:}

Purpose - This study discovers a three-step process for building contextual ambidexterity into interorganizational IT-enabled service processes through developmental interventions.

Design/methodology/approach - A longitudinal action research project was conducted. The empirical study consisted of three consecutive developmental interventions to support the collaborative development effort of an IT company and its customer network to efficiently serve their present and future customers. The data consists of process modeling and simulation workshop discussions, interviews, observation, and archival data. The development effort was studied for over a year.

Findings - The study shows that the three developmental interventions acted as a process for balancing the exploration-exploitation tension in inter-organizational service processes. The sequential interventions facilitated the studied organizations in (1) crossing the inter-organizational knowledge boundaries and creating shared domain knowledge, (2) creating common understanding of the collaborative IT-enabled service processes, and (3) co-developing the coordination mechanisms that are essential for the continuous exploration and exploitation of the new ideas in the future collaborative service processes. These three steps built capacity for the inter-organizational management system to achieve synergies between goals, resources, and activities in the inter-organizational collaboration.

Originality/value - The study contributes to the understanding on the process of building interorganizational ambidexterity. The study presents a three-step process for building inter-organizational contextual ambidexterity into the IT-enabled service processes through developmental interventions. Research on inter-organizational contextual ambidexterity is combined with research on coordination and knowledge management.

Keywords: Inter-organizational, ambidexterity, knowledge boundary, coordination, intervention, action research, facilitation, collaboration 
Article Classification: Research paper

\section{Introduction}

In global competition, organizations have to collaborate in inter-organizational business processes to be able to efficiently fulfill the needs of their common customers (Hagel and Brown, 2005). Often also the customers collaborate in the networked service provisioning processes. The competitive pressure compels organizations not only to efficiently meet the needs of present customers, but also to innovate the needs of future customers (Smith and Tushman, 2005; Martini et al., 2013). These exploitative and explorative activities create tensions and contradictory knowledge management processes in inter-organizational business processes.

The requirement for ambidexterity, i.e. balancing the tension between explorative and exploitative activities, is a tremendous management challenge even within a single company (Lavie et al., 2010). It becomes highly challenging in inter-organizational business processes, where parties' differences in norms, values, and interests pose challenges for collaborative knowledge management (Swan et al., 1999). The partners' differences in background knowledge, expertise, and skills create knowledge boundaries, which hinder effective collaboration (Carlile, 2004; Child, 2005). The embedded and tacit nature of background knowledge also creates obstacles that need to be overcome when integrating various expertise between organizations (Levina and Vaast, 2005).

Thus, ambidexterity in an inter-organizational relationship is not only the act of balancing exploitative and explorative activities, but also coordinating the internal and external "knowledge bases" (Raisch et al., 2009:690) necessary for balancing exploration and exploitation. Current ambidexterity research provides understanding on how to balance exploration and exploitation in an inter-organizational relationship through contextual ambidexterity (Im and Rai, 2008, 2014), but lacks understanding on how to coordinate the internal and external knowledge bases in inter-organizational collaboration (Raisch et al., 2009). This study addresses the research gap by combining theories on inter-organizational contextual ambidexterity (Im and Rai, 2008, 2014) with theories on coordination (Thompson, 1967; Okhuysen and Bechky, 2009).

Coordination research provides understanding on the mechanisms for coordinating knowledge, but fails short in showing how to manage the knowledge boundaries faced in inter-organizational business processes where different knowledge bases are present. Knowledge management research (Carlile, 2004), together with research on developmental interventions (Okhuysen and Eisenhardt, 2002; Smeds, 2003) are needed to understand the phenomenon and the methods of crossing the knowledge boundaries for inter-organizational ambidexterity.

Literature on ambidexterity is neither clear about the role of managers in managing ambidexterity (O'Reilly and Tushman, 2013), not to mention their role in the inter-organizational context. This study addresses this research gap through its focus on the process for building contextual ambidexterity in collaborative service processes.

The study investigates the following research question: How to build contextual ambidexterity into interorganizational IT-enabled service processes? To understand the phenomenon in practice, a longitudinal action research project was conducted. The empirical study consisted of three consecutive developmental interventions to support the collaborative development effort of an IT company and its customer network to efficiently serve their present and future customers by co-developing IT systems and business of their ITenabled service processes. By examining the use and outcomes of the developmental interventions, the study answers to the call for research on the mechanisms that balance exploitation and exploration (Lavie et 
al., 2010). The empirical setting of co-developing IT systems and business provides an opportunity to understand the phenomenon of crossing knowledge boundaries when building inter-organizational ambidexterity. In addition, the context provides a unique opportunity to contribute to inter-organizational ambidexterity theory. This is important as "few scholars have investigated exploration and exploitation through inter-organizational knowledge sharing..." (Stadler et al., 2014:180).

This study makes a theoretical contribution by combining research on inter-organizational ambidexterity with research on coordination and knowledge management. The study shows that when building interorganizational ambidexterity into the IT-enabled service processes, different knowledge boundaries need first to be crossed to develop shared domain knowledge. This enables inter-organizational co-development of coordination mechanisms for continuous exploration, and for the exploitation of the new ideas in the organizations' IT-enabled service processes.

The study makes another theoretical contribution by adding to the understanding on the process of building inter-organizational ambidexterity. The study shows that the developmental interventions triggered a process of three consecutive steps for building inter-organizational contextual ambidexterity. The interventions improved the capacity of the inter-organizational management system to achieve synergies between exploration and exploitation of goals, resources, and activities in the inter-organizational IT-enabled service processes. The interventions facilitated the studied organizations in (1) crossing the interorganizational knowledge boundaries and creating shared domain knowledge, (2) creating common understanding of the collaborative IT-enabled service processes, and (3) co-developing the coordination mechanisms that are essential to manage the continuous exploration and exploitation of the new ideas in the future collaborative service processes. The managerial implication of the study is that the managers of the networked organizations need to be aware of the knowledge management challenges and apply the three steps to build inter-organizational ambidexterity when co-developing IT and business.

\section{Theoretical background}

Theoretical background draws from three different theoretical lenses to understand how contextual ambidexterity is built into the inter-organizational IT-enabled service processes. The lenses are introduced in three separate sub-paragraphs. The first paragraph introduces the concept of inter-organizational contextual ambidexterity. The second paragraph discusses coordination of inter-organizational explorative and exploitative activities. The third paragraph presents how shared domain knowledge between organizations is created through developmental interventions.

\subsection{Inter-organizational contextual ambidexterity}

Within an organization, ambidexterity refers to the organization's capability to simultaneously exploit existing internal knowledge and explore new external knowledge (Raisch et al., 2009). Exploitation is defined as "building on the organization's existing knowledge base", whereas exploration is defined as shifting away from the organization's current knowledge towards creating new knowledge from external sources (Lavie et al., 2010:114). Rather than thinking of ambidexterity as a dichotomy, it can be thought as an explorationexploitation continuum (Lavie and Rosenkopf, 2006; Lavie et al., 2010). For this reason, the process of balancing, i.e., how organizations aim for a point on the "continuum that corresponds to its natural balance", becomes the key issue for the management of ambidexterity (Lavie et al., 2010:127). For example, an internal organizational or external environmental change requires adjustments to the levels of exploration and exploitation (Lavie et al., 2010).

The two mechanisms for achieving ambidexterity within an organization are structural and contextual (Gibson and Birkinshaw, 2004; Andriopoulos and Lewis, 2009; Im and Rai, 2014). The structural mechanism 
functions through spatial or temporal differentiation, after which integration is required. Differentiation buffers the explorative activities from the exploitative activities and helps managing bounded rationality, because differentiation ensures focus. The use of the structural mechanism requires reintegration mechanisms from the higher management level. (ibid.)

The contextual mechanism emphasizes that exploration and exploitation can be achieved at the same time by combining the approaches (Gibson and Birkinshaw, 2004; Smith and Tushman, 2005; Andriopoulos and Lewis, 2009; Eisenhardt et al., 2010). The approaches are combined through a supportive organization context of systems and processes that allow individuals both to explore and exploit simultaneously. This means that the whole organization is "working toward the same goals" and is able to reconfigure its activities "quickly to meet changing demands in the task environment". (Gibson and Birkinshaw, 2004:209)

In inter-organizational collaboration, achieving structural ambidexterity incurs costs because of the plural systems of governance. Costs are also generated from the need for mechanisms of reintegrating the differentiated explorative and exploitative activities. Contextual ambidexterity has thus become a successful alternative to structural ambidexterity for balancing the tensions between explorative and exploitative activities especially in the inter-organizational collaboration (Im and Rai, 2014). Inter-organizational contextual ambidexterity is defined as the capacity of the inter-organizational management system to achieve synergies between exploration and exploitation of goals, resources, and activities for the interorganizational collaboration. The management system includes culture, processes, and routines. (Im and Rai, 2008, 2014:74)

Ambidexterity literature is still unclear about the role of managers' behavior in managing ambidexterity (O'Reilly and Tushman, 2013). However, prior research indicates that management's role in developing intraorganizational ambidexterity is important. For example, the manager can have an interventionist role by focusing on promoting new ideas and building energy throughout the business processes. (Gibson and Birkinshaw, 2004; Smith and Tushman, 2005; Birkinshaw and Gupta, 2013) However, the managers of the collaborating partners may face challenges in acting as interventionists in the inter-organizational business processes. For example, the organizations' knowledge bases may differ which hinders knowledge exchange and co-creation (c.f. Stettner and Lavie, 2013). Furthermore, different business interests and power positions pose challenges for managers in managing inter-organizational collaboration (c.f. Weick et al., 2005). External, neutral facilitators may be called in to support the building of inter-organizational contextual ambidexterity.

\subsection{Coordination of inter-organizational explorative and exploitative activities}

Managing ambidexterity requires the coordination of explorative and exploitative activities (Raisch et al., 2009). Coordination is defined as the integration of organizational activities towards a common goal when taking into account the information-processing demand, task interdependencies, and uncertainty stemming from the environment (Thompson, 1967; Faraj and Xiao, 2006). Coordination mechanisms and organizational structures seek for the best possible fit with the business environment to maximize efficiency (Thompson, 1967). However, once the coordination mechanisms have been aligned with current contingencies of the business environment, they soon need to be updated because alignment with the changing environment is a dynamic process (Solaimani and Bouwman, 2012). In other words, the coordination mechanisms, which once suited the environmental contingencies, may need to be adjusted if they do not support the new environmental contingencies followed by the dynamic shift from exploitation to exploration or the other way around. Moreover, the use of one specific coordination mechanism does not rule out the use of other mechanisms (Adler, 1995). Rather, the coordination mechanisms are additive (Thompson, 1967). 
In inter-organizational processes, the coordination of explorative activities, and thus knowledge management, is hard because of parties' differences in norms, values, and interests (Swan et al., 1999). However, if the collaborating organizations are able to coordinate their explorative activities, the resulting innovations are likely to be radical: the creation of radically new knowledge and innovations is triggered at inter-organizational boundaries, e.g. at the boundary between public and private organizations (Dougherty and Dunne, 2011).

Inter-organizational explorative activities involve high levels of uncertainty and require learning (Sheremata, 2000; Stadler et al., 2014). In other words, explorative activities strive for the creation of new knowledge and experimentation to create innovation (Andriopoulos and Lewis, 2009). Alliances aimed at exploration have been found to have difficulties in coordinating tacit knowledge between organizations (Rothaermel and Deeds, 2004). On one hand, exploration increases reciprocal interdependencies between the exploring parties, and the coordination of their explorative activities requires mutual adjustment (Thompson, 1967; Sheremata, 2000). On the other hand, inter-organizational exploitative activities need coordination for efficiency, which can be achieved through standardization of work, rules, and planning (Thompson, 1967; Mintzberg, 1979).

According to Okhuysen and Bechky (2009), coordination mechanisms, such as plans, rules, boundary objects, roles, routines, and proximity create three integrating conditions to coordinate the interdependent individuals performing the work in organizations. The first condition is accountability that refers to people being accountable for their contribution and making other people accountable for their part of the task. The second condition is predictability which means that people know which subtasks constitute the task, and in which order they need to be performed. The third condition is common understanding about the task at hand, how to execute it, and the objectives of the task. Through these three integrating conditions people collectively accomplish their interdependent work tasks in the organization. (ibid.)

\subsection{Creating shared domain knowledge between IT provider and customer in inter- organizational IT system and business co-development through developmental interventions}

The co-development of IT systems and business requires that the IT provider and the customer together enter into the explorative activities of innovation and back to exploitative activities to implement the new ideas. During the co-development, a high level of communication is needed between the IT provider and the business process owner, i.e. the customer to prevent wrong assumptions (Reich and Benbasat, 2000; Barki and Hartwick, 2001; Hornik et al., 2003). Through communication, the parties try to make sense what the situation is and what kinds of actions it requires (Weick et al., 2005). Communication between the parties should lead to shared domain knowledge, which means that the parties understand each other's key processes and are able to participate in them. Shared domain knowledge (also referred to as common knowledge) helps the parties in their explorative and exploitative activities of the collaborative process. (Reich and Benbasat, 2000; Carlile, 2004)

The challenge in creating shared domain knowledge are knowledge boundaries between the parties (Garrity, 2001; Carlile, 2004). The knowledge boundaries are manifested in the lack of shared language and common understanding, and/or differences in working methods, which may originate from differences in educational and professional background, work experience, concerns, and language (Kaiser and King, 1982; Taylor-Cummings, 1998). The customer's business knowledge differs from the IT provider's technical knowledge, and their work processes also differ which easily leads to misunderstandings between the parties and to the development of IT systems that do not meet customer's business needs (Al-Karaghouli et al., 2005). Ambidexterity literature does not discuss how the knowledge boundaries can be crossed. For this 
reason, we need to look at knowledge management research on creating shared domain knowledge through developmental interventions.

Creating an environment where shared domain knowledge can grow is highly important (Reich and Benbasat, 2000). Developmental interventions consisting of business process modeling and simulation workshops can create shared contexts where knowledge can be shared and created between the parties. The shared context can be described as a 'ba' (Nonaka et al., 2000) where open atmosphere encourages the inter-organizational explorative activities of knowledge co-creation. In information systems design, business process modeling has been recognized important for knowledge sharing (Aguilar-Savén, 2004; Barjis, 2008) and for developing business processes (Rub and Issa, 2012).

Developmental interventions have been shown to help knowledge integration between groups (Okhuysen and Eisenhardt, 2002). The interventions of simulation workshops bring people from separate organizations together to share tacit knowledge, increase process understanding and shared domain knowledge between the participants, and facilitate collaborative exploration for evolutionary change (Haho, 2004). The simulation workshop enables the conversion of the participants' tacit process knowledge into shared explicit knowledge (Feller et al., 2005) by using boundary objects, such as visual process models (Levina and Vaast, 2005; Xu, 2009). The facilitator of the intervention supports the discussion towards a common goal and common understanding of the object of development, and helps to create change in the organizations (Weick and Quinn, 1999; Jaatinen and Lavikka, 2008). Figure 1 illustrates how developmental interventions help in crossing knowledge boundaries between the parties towards shared domain knowledge.

\section{TAKE IN FIGURE 1}

\section{Research methodology}

\subsection{Action research through three developmental interventions}

A longitudinal action research project was conducted because the study aimed at understanding and explaining a complex social process of creating inter-organizational ambidexterity. This phenomenon took place in its real life context but required introducing changes into it in order to initiate the process. (Baskerville, 1997)

Action research provided access to rich, in-depth empirical data. Organizations taking part in the action research project were more willing to share their practical problem with the researchers when the researchers promised to help the companies in solving their challenge. Thus, action research approach was also chosen because it combines two objectives: on one hand the solving of a practical problem and on the other hand the development of scientific knowledge (Hult and Lennung, 1980; Gummesson, 2000). In this study, the practical problem was to support the organizations' collaborative effort in better serving their future and present customers by co-developing the IT systems and business of their IT-enabled service processes. The scientific knowledge, on the other hand, aimed at understanding how to build interorganizational contextual ambidexterity into the IT-enabled service processes. The inter-organizational, ITenabled service processes provided a good empirical setting for understanding how to cross knowledge boundaries when building inter-organizational ambidexterity.

Balancing explorative and exploitative activities in inter-organizational business processes requires learning. Action research was also a useful approach because it can create structures for organizational learning from experience (Chisholm, 2001). In addition, action research helped in understanding how the studied organizations function in practice (Avison et al., 1999). Action research is an "emergent inquiry 
process", which is not possible to control and where data shifts through intervention in collaboration with practitioners (Shani et al., 2012:51).

The researched phenomenon consisted of the collaborative development effort of an IT company and its customer network of three competing finance service alliances, each owning shares of the IT-company. The development effort was studied for over a year. The alliances A, B and C each consist of several independent service companies (ISC) that provide their services through their local sales units (LSU). The employees of the service companies and their local sales units, as well as the end-users of the financial services, use the IT provider's IT systems in the service provisioning process. Figure 2 illustrates the parties in the study, i.e. the three-layer business network of the three alliances with their jointly owned IT provider organization.

\section{TAKE IN FIGURE 2}

Action research approach was implemented through three developmental interventions. A process development method was applied in each intervention. The method consists of facilitation, boundary objects, and process modeling and simulation workshops for knowledge sharing and creation (Smeds, 2003).

\subsection{Data collection}

Data was collected during each intervention from several data sources: (1) interviews, (2) process modeling and simulation workshops, (3) observation during workshops, and (4) archival data. Fifteen semi-structured interviews were conducted altogether during the three interventions. Each interview lasted between 1 and 1,5 hours. The objective of the interviews in the first intervention was to understand the context of the study, the challenges the studied organizations were facing, and what to do to solve the challenges. The focus of the interviews in the second intervention was to understand how the ideas generated in the first intervention were implemented, what the current inter-organizational challenges were, and how to solve those challenges. In the third intervention, the interviews were conducted to understand how the ideas generated in the second intervention were implemented and how to ensure that the companies innovate also in the future but also ensure efficiency in their collaborative service provisioning processes.

The interviewees were selected using snowball sampling (Biernacki and Waldorf, 1981) in cooperation with key representatives from the studied organizations. The interviewees represented the following organizational levels in the IT provider and the customer network companies: middle-managers, product managers, project managers, domain experts, and clerical employees. The same people from the companies participated in the interviews and process modeling and simulation workshops.

The process modeling and simulation workshops had different aims during each intervention. The objective of the workshops during the first intervention was to ensure that the studied parties share both explicit and implicit knowledge and develop their collaborative service processes. During the second intervention, the workshops aimed at creating common understanding between the parties about how to co-develop the business and IT in their collaborative IT-enabled service processes. Finally, the workshops during the third intervention were arranged to decide on the coordination mechanisms between the organizations to ensure the service processes meet the needs of both current and future customers.

The workshops were audio and video recorded by the researchers. Also observation took place and notes were taken during the workshops. The observation of the workshops as well as the archival data from the companies gave a holistic understanding of the study's background (Marshall and Rossman, 1995). Interview data was triangulated with observation and archival data to improve the study's accuracy (Bingham and Eisenhardt, 2011). Table 1 presents the specific business processes to be developed, data collection points, and the informants in each consecutive developmental intervention. 


\section{TAKE IN TABLE 1}

\subsection{The role of the action researchers}

Four action researchers from the university, i.e. external change agents (Birkinshaw et al., 2008) acted as facilitators in the three interventions. The interventions were realized between the years 2006 and 2007. Each intervention built on the findings of the previous one. The first author of this paper acted as the responsible researcher of the first and the third interventions. She took part in every data gathering event: interviewing parties and facilitating the process modeling and the simulation workshops. Also the third author of this paper engaged in data gathering.

The researchers collaborated with the people of the IT provider organization and the customer network, but with no "hidden agenda", except facilitating the collaborative development effort and dialogue of the participants. This is in line with the action research approach where the role of the action researcher is to form "a consensus on the direction of change through research, feedback, and mutual discussion" (Child, 2005:304). The limitation of a possible informant bias was taken into account by carefully selecting 'highknowledge' informants (Freeman et al., 1987). These representatives from the studied organizations were in charge of the collaborative development of the service processes. They had to report to their managers in written reports, and thus their recall of the collaborative activities during the research period can be considered quite accurate.

The interventions were planned and organized in collaboration with the studied organizations: setting the goals for the intervention, modeling and visualizing the selected business processes, and interviewing the parties. The researchers prepared and organized a simulation workshop day, analyzed the results, and gave feedback to the studied organizations in the form of a written report. During the simulation workshops, the researchers facilitated the studied representatives' discussion about their collaborative, IT-enabled service processes in a group dialogue in front of the visual business process models.

The process models functioned as platforms, i.e. boundary objects (Levina and Vaast, 2005) to share knowledge between the provider and the customer network representatives. The models were intended to stimulate discussion and develop a common understanding of the activities in the service processes. The visual notation of the process models created a shared language for communication. The models were drawn using a flowchart (sometimes also referred to as an activity diagram) technique because its notation provides an easy to understand visualization of the service processes. In addition, the flowchart technique is most useful when dealing "with processes that need a high level of detail" (Aguilar-Savén, 2004: 134).

\subsection{Data analysis}

By following the logic of abductive scientific reasoning (Dubois and Gadde, 2002) in interpretive action research, the researchers' understanding progressed as a continuous dialogue between their preunderstanding originating from existing theoretical knowledge and research data that was collected during three different time points as depicted in the table 1 (Mantere and Ketokivi, 2013). Insights emerging from earlier data collection impacted the next round of data collection, i.e., the next intervention. For example, the feedback from the studied organizations, after the first intervention, affected the boundaries, the selection of interviewees, and timing of the second intervention. Also the findings from the second intervention affected the planning and implementation of the third intervention. These represent the iterative action research cycles of identifying the problems, planning what to do next, acting to induce change, and evaluating the outcomes of action (Coghlan and Brannick, 2005).

During each intervention, analysis of the process modeling workshop data affected the interview questions. When specific challenges were found during process modeling, their reasons could be more 
thoroughly examined during interviews. Also the analysis of the interview data affected the planning of the simulation workshop. Thus, it can be argued that the researchers conducted within-intervention analysis to uncover inter-organizational tensions.

The interviews and the process modeling and simulation workshop discussions were audio recorded and transcribed word for word after each developmental intervention. The transcriptions and the observation notes amounted into altogether 886 pages of text. The text was content analyzed by annotating and classifying them into eight theoretically grounded themes: inter-organizational explorative activities, interorganizational exploitative activities, coordination, knowledge boundaries, intervention, facilitation, boundary object, and common understanding. The inter-organizational explorative activities were operationalized as activities where employees from at least two organizations co-create radically new development ideas on how to improve the IT-enabled service processes, whereas in exploitative activities the organizations only refine their existing processes and routines of the IT-enabled service processes. Because the research aimed at understanding the temporal order of how inter-organizational ambidexterity is built, the themes were further coded based on when that particular data was produced. For example, data could be coded as taking place during the process modeling session of the second developmental intervention.

\section{Findings and discussion}

The findings are discussed in five sub-paragraphs. The first sub-paragraph introduces the development challenge and the tensions the studied organizations were facing. The second paragraph presents how the representatives of the organizations crossed the knowledge boundaries and created shared domain knowledge. The third paragraph shows how common understanding about the future IT and business requirements were co-created, whereas the fourth paragraph explains how the studied organizations codeveloped coordination mechanisms for explorative and exploitative activities for the future. The fifth paragraph summarizes the findings and portrays the process for building inter-organizational contextual ambidexterity.

\subsection{Setting the scene: The development challenge and tensions of the studied organizations}

The IT provider and the customer network had collaboratively served their common end-users through shared service provisioning processes for several years. The customer network was globally among the earliest and most advanced adopters of IT systems. However, over the years, new IT systems with poor interoperability were built in the customer network's business processes for almost every new business need. In addition, the customer network's business needed to be developed to meet the new EU regulations.

The development challenge of the IT provider and its customer network was to collaboratively develop their service processes by co-developing the IT systems and the business underlying it, to better serve the network's common present and future end-users. This implies that the initial need for balancing explorative and exploitative activities was due to environmental exogenous pressures (Lavie et al., 2010).

The development challenge brought different tensions between the parties. For example, the parties needed to manage the co-existence of conflicting exploration and exploitation goals in their shared service provisioning processes. In addition, the parties struggled with sharing resources to both explorative and exploitative activities, but also with understanding how to efficiently achieve inter-organizational explorative activities. It can be argued that the development challenge reflected the typical learning tension of building upon and at the same time destroying the past to create the future (Lewis, 2000; Smith and Lewis, 2011).

The IT system provider and the customer network had applied many coordination mechanisms to continuously develop their collaborative service processes by either focusing on developing the IT systems 
or the customer networks' business. The coordination mechanisms included support lines using telephone and email, training sessions organized by the IT provider, feedback forms on the Internet and in the customer relationship management system, and reference groups organized by the customer network twice a year.

However, these coordination mechanisms, which were part of the inter-organizational management system, were no longer sufficient when the radical changes in the competitive environment and IT called for innovation. The current IT systems and the customer network's business had to be radically changed to meet the needs of present and future customers. In other words, the studied parties needed to pay special attention to exploration to develop the IT systems and the business of the collaborative service provisioning processes, but also make sure they enter back into exploitative activities after exploration to make sure new development ideas are implemented to efficiently serve the present and future common customers, i.e., the end-users. These findings indicated that the current inter-organizational management system no longer provided synergies between exploration and exploitation of goals, resources, and activities in the interorganizational service provisioning processes (Im and Rai, 2008, 2014).

The following quotes illustrate that the current explorative activities to develop the IT systems and the business processes through the coordination mechanisms were not adequate anymore but they needed to be developed. Furthermore, both parties had prejudices against each other, which also indicate that the inter-organizational management system consisting of culture, processes, and routines was not achieving synergies between explorative and exploitative activities and needed to be improved.

"The current information systems are not well integrated. One needs to add the same information twice in different systems and the systems do not support our way of working. The training sessions organized for us are not enough. Why are the development ideas that we give the IT provider not implemented in the systems?" (A customer network representative)

"The customer network's way of thinking differs a lot from ours. They see new things from a different perspective than we do. It is sometimes difficult to understand each other's perspectives. They come here twice a year in the reference groups to handle these development ideas; it is not always the world's most efficient way of working together." (An IT provider representative)

As a result, the IT system provider and the customer network wanted to co-develop, i.e., develop simultaneously, the IT systems and the business to improve the collaborative service processes. The logic behind co-development was the understanding that the customer network is the expert in its service processes, while the IT provider is the expert in the latest information technology, and this partly explicit and partly tacit knowledge needed to be shared between the parties to co-create innovative new service processes. The co-development took place during the requirements engineering phase of the IT systems development project, and it required that the companies entered into inter-organizational exploration.

\subsection{Crossing the knowledge boundaries between the parties and creating shared domain knowledge}

The analysis of the process modeling workshop discussions and interview data revealed the lack of shared language for communication, different working backgrounds, and organizational working cultures between the companies, which is typical in the inter-organizational collaboration (Garrity, 2001; Carlile, 2004). The lack of shared language, shared ways of working, and different working backgrounds created knowledge management tensions between the parties when they were expected to explore to co-create their IT-enabled service processes. The parties did not understand each other. For example, the IT provider used IT-based 
terminology and concepts which were not familiar to the customer and the other way around. They neither knew each other's work processes. The knowledge boundaries prevented the parties from interorganizational explorative activities which require knowledge sharing and learning (c.f. Sheremata, 2000; Stadler et al., 2014).

Therefore, the first developmental intervention was planned to focus on sharing knowledge between the parties about the current and ideal service processes and how the IT systems could support the processes. On one hand, the representatives of the customer network's companies shared their business process knowledge on how the current service processes functioned, what the current problems and needs were, and what the companies' goals and possible future needs were. On the other hand, the representatives of the IT provider company shared their IT knowledge on the possibilities and limitations the information technology posed to the processes, the possible costs of implementing certain functions, and the possible schedule of the development project.

At the end of the first process simulation workshop, the representatives of the studied organizations discussed that they now better understood each other's work processes and how the collaborative service processes work, i.e. how the IT systems and business were interrelated. It can be argued that the representatives of the studied organizations created shared domain knowledge (Reich and Benbasat, 2000; Carlile, 2004) but they first needed to cross the different knowledge boundaries (c.f. Carlile, 2004). The following quotes illustrate the result of the first developmental intervention.

"The common and complete understanding about each other's work processes that we gained is a good starting point for the development." (A customer network representative]

"The process model helped in understanding the systemic nature of the issues and how IT systems and customer network's business are interrelated. (An IT provider representative)"

The quotes also illustrate that the culture of the inter-organizational management system was improved through the business process modeling and simulation workshops. After the first developmental intervention the parties had improved the culture of sharing and co-creating knowledge. The workshops were organized and discussions were facilitated by the action researchers who had interviewed the participants and planned the topics of the discussions. The facilitating action researchers asked clarifying questions, and made sure that the discussion was focused on right issues. The facilitators acted as boundary spanners (Lawrence and Lorsch, 1967; Gittell and Weiss, 2004; Levina and Vaast, 2005) whose role were to help in balancing the explorative and exploitative activities between the parties. Without the facilitators it might have been possible that the different parties would not have shared their knowledge in a way that would be understandable to the other party. An outsider is usually better in addressing difficult questions and analyzing the findings more objectively than the parties involved in the process, as Weick and Quinn (1999) discuss.

\subsection{Co-creating common understanding about the future IT and business requirements of the collaborative service processes}

During the second developmental intervention, the parties collaboratively invented the common end-users' future business needs, and the technological solutions to support the fulfilment of the needs. The facilitated business process modeling workshop and the process simulation resulted in common understanding, i.e. shared meanings (Weick, 1995), between the parties about each parties' future work processes and the requirements of the end-users' future needs, and how the IT systems could support them. These findings 
implied that the parties improved both culture and processes of the inter-organizational management system (c.f. Im and Rai, 2014).

The following quotes were expressed at the end of the second simulation workshop. They illustrated the co-created common understanding between the parties about the future work processes and future customers' needs. However, the quotes also illustrate the tensions that remained. For example, the representatives agreed that they cannot only change the IT systems but also the customer's business processes required changes which usually initiate organizational behavior challenges that also need to be managed.

"A new information system alone cannot change the way of working, but the change itself needs to be managed first." (A customer network representative)

"I started to understand the wholeness and the requirements for the IT system. Service oriented architecture will support the customers' changing business demands." (An IT provider representative)

"There needs to be a continuous dialogue between us and the customer network. The more there is contact with the customer network, the more it shares understanding between us. Common understanding is a prerequisite for collaboration." (An IT provider representative)

The process model visually represented which tasks needed to be executed by whom and when. Moreover, common understanding about the future business and IT system requirements could be created because the process models and facilitated discussion helped the parties to share information and create new knowledge. Thus, it can be argued that the process models acted as boundary objects for developing common understanding between the parties (Levina and Vaast, 2005). Process models enabled the externalization of knowledge and helped the parties to understand their collaborative service processes, which corroborates the prior finding by Zollo and Winter (2002). The following quotes illustrate how process models helped the creation of common understanding about the future requirements of the service processes between the parties. The quotes originate from two interviews of the third intervention.

"My process thinking was enhanced. I understand better how some of the sub processes work. We gained many good development ideas but also smaller ones that can be implemented in the near future quite easily." (A customer network representative)

"I understood the complexity of the process' wholeness and the smaller steps that can be taken to develop it further." (An IT provider representative)

The quotes also hint that the process models and facilitated discussions during the first and second developmental interventions had developed three integrative conditions for the future exploration and exploitation in the service processes. First, they created accountability as the process models visually represented who is responsible for which tasks in the service processes. Second, they created predictability as the process models visually represented when and in which order the tasks in the service processes are to be executed. Third, they created common understanding between the parties about the future requirements of the service processes. (c.f. Okhuysen and Bechky, 2009) 
4.4 Co-developing coordination mechanisms to ensure exploration and exploitation in the future During the third developmental intervention, the parties discussed coordination mechanisms for managing continuous exploration in the collaborative service processes. The parties decided to keep some of the already existing mechanisms, such as feedback forms in the customer relationship management system, reference groups organized by the customer network twice a year, and training sessions organized by the IT provider. Additionally, they co-created the idea to use collaborative process modeling workshops, probably organized by a third-party organization. The workshops and other coordination mechanisms represent coordination through planning and mutual adjustment (c.f. Thompson, 1967; Mintzberg, 1979).

Furthermore, the parties co-developed coordination mechanisms, such as 'collaboration groups' and 'a core group', for the continuous exploration and exploitation of the new ideas in the collaborative service processes in the future. The co-developed coordination mechanisms represent standardization and planning (c.f. Thompson, 1967; Mintzberg, 1979). These findings indicated that the parties improved both the routines and the processes of the inter-organizational management system (c.f. Im and Rai, 2014). The following quotes were captured at the end of the third simulation workshop. They illustrate that the parties regarded continuous communication between the parties essential for the functioning of their collaborative service provisioning processes.

"We need collaboration groups between the companies. Both parties need to be listened during implementation. Testing is needed from the common end-users' point of view." (A customer network representative)

"Information sharing and discussion between the parties need to be increased and we need a core group to take responsibility for the development." (An IT provider representative)

After the third intervention, the researchers conducted a follow-up interview to understand the effects of the interventions on the development of the parties' collaborative service processes. According to the IT representative, the next step in developing the collaborative service processes would be to understand the service process patterns on a more detailed level to develop the software supporting customer network's business decisions. This finding suggests that the co-development of IT systems and business for efficient inter-organizational exploitation requires time and detailed knowledge on business decisions. The IT provider also mentioned that one tension remained between the customer and the IT provider. The customer still expected the changes in the IT systems to take place immediately, although the IT provider had tried to explain the customer that IT development takes time and all the changes may not be reasonable to implement if their implementation cost is higher than their expected financial and other benefits. The following quote illustrates these findings.

"We identified the business requirements and the business processes with your help through the process modeling and simulation workshops. However, that is just the top of an iceberg. We still need to do a lot of development with the subsystems. ... we need to take these modeled processes and go deeper into them. We need to know in more detail what information goes in and out of the system." (An IT provider representative)

\subsection{A process for building inter-organizational contextual ambidexterity}

The studied organizations had been together serving the common end-users for a long time. The capacity of their inter-organizational management system to achieve synergies between exploration and exploitation of 
goals, resources, and activities in the inter-organizational collaboration had been declined over time. This illustrates the prior finding by Im and Rai (2014). The parties faced tensions between exploration and exploitation of goals, resources, and activities. However, the findings of the study imply that a third-party may facilitate the improvement of the capacity of the inter-organizational management system through developmental interventions, and thus alleviate the tensions between the parties.

During the first intervention, the knowledge boundaries between the organizations needed to be crossed by sharing IT and business knowledge. This led to the creation of shared domain knowledge (Reich and Benbasat, 2000; Carlile, 2004) and enabled the parties to enter into the inter-organizational explorative activities. During the second intervention, the parties engaged into the explorative activities of co-creating common understanding about the IT and business requirements of the collaborative service processes in the future. These findings suggest that the first two interventions improved the culture and processes of the inter-organizational management system (c.f. Im and Rai, 2014).

Finally, during the third intervention, the parties co-developed coordination mechanisms for continuous exploration and for the exploitation of the new ideas in the collaborative service processes in the future. This finding suggests that the third intervention improved the routines and processes of the management system. Together the three developmental interventions improved the capacity of the culture, processes, and routines of the inter-organizational management system to achieve synergies between exploration and exploitation of goals, resources, and activities in the collaborative service processes. Thus, the organizations built inter-organizational contextual ambidexterity, as defined by Im and Rai (2014). The three developmental interventions, consisting of business process modeling and simulation workshops, acted as a three-step process for building inter-organizational contextual ambidexterity (See figure 3).

\section{TAKE IN FIGURE 3}

\section{Conclusions}

This study has addressed the research gap in understanding how contextual ambidexterity is built in an interorganizational IT-enabled service process, i.e., how exploitative and explorative activities are balanced and the internal and external knowledge bases coordinated. The study explored the process of building interorganizational contextual ambidexterity through developmental interventions. A longitudinal action research project was conducted. The empirical study consisted of three consecutive developmental interventions to support the collaborative development effort of an IT company and its customer network to efficiently serve their present and future customers by co-developing IT systems and business of their IT-enabled service processes. The antecedent was the finding that their inter-organizational management system no longer could efficiently balance exploration and exploitation (c.f. Im and Rai, 2014).

The study contributes theoretically by combining research on inter-organizational contextual ambidexterity to research on coordination and knowledge management. The study shows that when building inter-organizational contextual ambidexterity into the inter-organizational IT-enabled service processes, different knowledge boundaries needed to be first crossed to develop shared domain knowledge. This enabled the inter-organizational co-development of coordination mechanisms for continuous exploration, and for the exploitation of the new ideas in the collaborative service processes in the future.

The paper also theoretically contributes by adding to the understanding on the process of building interorganizational contextual ambidexterity. The study showed that the developmental interventions through business process modeling and simulation workshops acted as a three-step process for balancing gradually the inter-organizational exploitation-exploration tension in the studied organizations' collaborative service 
processes. The process represents a management innovation, which can be applied to strive for the interorganizational goals (Birkinshaw et al., 2008; Martini et al., 2013). However, it needs to be noted that the action researchers were important neutral actors in organizing the process modeling and simulation workshops and helping the organizations in sharing expertise (Weick and Quinn, 1999).

The study's interventions improved the capacity of the inter-organizational management system, namely the culture, processes, and routines, to achieve synergies between exploitation and exploration of goals, resources, and activities in the collaborative service processes (Im and Rai, 2008, 2014). The interventions facilitated the studied organizations in (1) crossing the inter-organizational knowledge boundaries and creating shared domain knowledge, (2) creating common understanding of the collaborative IT-enabled service processes, and (3) co-developing the coordination mechanisms that are essential for the continuous exploration and exploitation of the new ideas in the future collaborative service processes. These three steps seem to form a temporal sequence that needs to be followed in order to build contextual ambidexterity when co-developing IT and business in inter-organizational IT-enabled service processes. The managerial implication of the research is that the co-development involves challenging knowledge management issues of which tackling takes time and has to be managed consciously as a process. However, the results may not be generalized to other domains than the IT and business co-development of inter-organizational IT-enabled service processes. Further research should be conducted to understand what kinds of knowledge boundaries exist in other domains and how the knowledge boundaries in other inter-organizational domains can be crossed for building inter-organizational ambidexterity.

The study showed that the use of the visual business process models helped the parties to cross the knowledge boundaries and to create shared domain knowledge, which supports the findings by Reich and Benbasat (2000) and Carlile (2004). Business process models acted as boundary objects for domain knowledge creation (Levina and Vaast, 2005). The interventions also facilitated the collaborative development of the coordination mechanisms that enable the balance between the inter-organizational explorative and exploitative activities in the future. The study also addressed the research gap in understanding managers' role in managing inter-organizational ambidexterity by describing how the managers together with research facilitators first engaged in the creation of shared domain knowledge and development ideas and then in the decision making on how to manage the exploitative and explorative activities by coordination mechanisms in the future.

The study has three limitations. The first limitation originates from the participative role of the action researchers, which was necessary to gain access to the research site and collect data of interest. However, the role of the action researchers has been carefully explained to mitigate this possible limitation. The researchers facilitated the improvement of the capacity of the inter-organizational management system to achieve synergies between exploration and exploitation of goals, resources, and activities in the interorganizational collaboration in an emergent process. The interventions were called for by the studied organizations and planned together with them.

The second limitation is the possible subjective judgment of the researchers in interpretive and participative research. However, the research process, accumulation of results, and their analysis were described detailed to increase study's transparency. (Blichfeldt and Andersen, 2006) In addition, three researchers collaboratively collected data, analyzed it, and asked clarifying questions from the studied representatives when needed in every phase of the research process.

The third limitation is that no follow-up research has been conducted to verify how well the shared domain knowledge, common understanding, and coordination mechanisms created during the interventions helped in the later phases of the collaborative development of the service processes. Future research is necessary to investigate this question and also to examine whether the results helped the studied parties to 
think and act ambidextrously in their collaborative service processes in the future, which can be anticipated based on Andriopoulos and Lewis (2009). Furthermore, research should investigate whether and how the knowledge boundaries develop as the relationship between organizations matures, and how the codeveloped coordination mechanisms develop in response to enable knowledge co-creation also in the future. Further research is also needed to thoroughly understand the tensions in inter-organizational collaboration processes and to help managers in forecasting the possible challenges in building inter-organizational ambidexterity.

\section{References}

Adler, P.S. (1995), "Interdepartmental interdependence and coordination: The case of the design/manufacturing interface”, Organization Science, Vol. 6 No. 2, pp. 147-168.

Aguilar-Savén, R.S. (2004), "Business process modelling: Review and framework", International Journal of Production Economics, Vol. 90 No. 2, pp. 129-149.

Al-Karaghouli, W., Alshawi, S. and Fitzgerald, G. (2005), "Promoting requirement identification quality: Enhancing the human interaction dimension", Journal of Enterprise Information Management, Vol. 18 No. 2, pp. 256-267.

Andriopoulos, C. and Lewis, M.W. (2009), "Exploitation-exploration tensions and organizational ambidexterity: Managing paradoxes of innovation", Organization Science, Vol. 20 No. 4, pp. 696-717.

Avison, D., Lau, F., Myers, M. and Nielsen, P.A. (1999), "Action research", Communications of the ACM, Vol. 42 No. 1, pp. 94-97.

Barjis, J. (2008), "The importance of business process modeling in software systems design", Science of Computer Programming, Vol. 71 No. 1, pp. 73-87.

Barki, H. and Hartwick, J. (2001), "Interpersonal conflict and its management in information system development", MIS Quarterly, Vol. 25 No. 2, pp. 195-228.

Baskerville, R.L. (1997), "Distinguishing action research from participative case studies", Journal of Systems and Information Technology, Vol. 1 No. 1, pp. 24-43.

Biernacki, P. and Waldorf, D. (1981), "Snowball sampling: Problems and techniques of chain referral sampling", Sociological Methods and Research, Vol. 10 No. 2, pp. 141-163.

Bingham, C.B. and Eisenhardt, K.M. (2011), "Rational heuristics: The 'simple rules' that strategists learn from process experience", Strategic Management Journal, Vol. 32 No. 13, pp. 1437-1464.

Birkinshaw, J. and Gupta, K. (2013), "Clarifying the distinctive contribution of ambidexterity to the field of organization studies", The Academy of Management Perspectives, Vol. 27 No. 4, pp. 287-298.

Birkinshaw, J., Hamel, G. and Mol, M.J. (2008), “Management innovation”, Academy of Management Review, Vol. 33 No. 4, pp. 825-845.

Blichfeldt, B.S. and Andersen, J.R. (2006), "Creating a wider audience for action research: Learning from casestudy research", Journal of Research Practice, Vol. 2 No. 1, pp. 1-12. 
Carlile, P.R. (2004), "Transferring, translating, and transforming: An integrative framework for managing knowledge across boundaries", Organization Science, Vol. 15 No. 5, pp. 555-568.

Child, J. (2005), Organization - Contemporary Principles and Practice, Blackwell Publishing, Malden, USA.

Chisholm, R. (2001), "Action research to develop an interorganizational network", in Reason, P. and Bradbury, H. (Eds.),Handbook of Action Research, Sage Publications, London, UK, pp. 253-261.

Coghlan, D. and Brannick, T. (2005), Doing Action Research in Your Own Organization, Sage Publications, London, UK.

Dougherty, D. and Dunne, D.D. (2011), “Organizing ecologies of complex innovation”, Organization Science, Vol. 22 No. 5, pp. 1214-1223.

Dubois, A. and Gadde, L.-E. (2002), "Systematic combining: An abductive approach to case research", Journal of Business Research, Vol. 55 No. 7, pp. 553-560.

Eisenhardt, K.M., Furr, N.R. and Bingham, C.B. (2010), "Microfoundations of performance: Balancing efficiency and flexibility in dynamic environments", Organization Science, Vol. 21 No. 6, pp. 1263-1273.

Faraj, S. and Xiao, Y. (2006), "Coordination in fast-response organizations", Management Science, Vol. 52 No. 8, pp. 1155-1169.

Feller, J., Parhankangas, A.-L. and Smeds, R. (2005), "Inter-partner process learning in collaborative R\&D - A case study from the telecommunications industry", Production Planning \& Control, Vol. 16 No. 4, pp. 388-395.

Freeman, L.C., Romney, A.K. and Freeman, S.C. (1987), "Cognitive structure and informant accuracy", American Anthropologist, Vol. 89 No. 2, pp. 310-325.

Garrity, E.J. (2001), "Synthesizing user centered and designer centered IS development approaches using general systems theory", Information Systems Frontiers, Vol. 3 No. 1, pp. 107-121.

Gibson, C.B. and Birkinshaw, J. (2004), "The antecedents, consequences, and mediating role of organizational ambidexterity", Academy of Management Journal, Vol. 47 No. 2, pp. 209-226.

Gittell, J.H. and Weiss, L. (2004), "Coordination networks within and across organizations: A multi-level framework", Journal of Management Studies, Vol. 41 No. 1, pp. 127-153.

Gummesson, E. (2000), Qualitative Methods in Management Research, Sage Publications, California, USA.

Hagel, J. and Brown, J.S. (2005), "New forms of connection and coordination - process networks, loose coupling, and performance fabrics", The Only Sustainable Edge - Why Business Strategy Depends on Productive Friction and Dynamic Specialization, Harvard Business School Press, Boston, Massachusetts, pp. 79-97.

Haho, P. (2004), "Paths to deutero-learning through successive process simulations: A case study", Knowledge and Process Management, Vol. 11 No. 4, pp. 239-251. 
Hornik, S., Klein, G. and Jiang, J.J. (2003), "Communication skills of IS providers: An expectation gap analysis from three stakeholder perspectives", IEEE Transactions on Professional Communication, Vol. 4 No. 1, pp. 17-34.

Hult, M. and Lennung, S.-Å. (1980), "Towards a definition of action research: A note and bibliography", Journal of Management Studies, Vol. 17 No. 2, pp. 241-250.

Im, G. and Rai, A. (2008), "Knowledge sharing ambidexterity in long-term interorganizational relationships", Management Science, Vol. 54 No. 7, pp. 1281-1296.

Im, G. and Rai, A. (2014), "IT-enabled coordination for ambidextrous interorganizational relationships", Information Systems Research, Vol. 25 No. 1, pp. 72-92.

Jaatinen, M. and Lavikka, R. (2008), "Common understanding as a basis for coordination", Corporate Communications: An International Journal, Vol. 13 No. 2, pp. 147-167.

Kaiser, K.M. and King, W.R. (1982), "The manager-analyst interface in systems development", MIS Quarterly, Vol. 6 No. 1, pp. 49-59.

Lavie, D. and Rosenkopf, L. (2006), "Balancing exploration and exploitation in alliance formation", Academy of Management Journal, Vol. 49 No. 4, pp. 797-818.

Lavie, D., Stettner, U. and Tushman, M.L. (2010), "Exploration and exploitation within and across organizations", The Academy of Management Annals, Vol. 4 No. 1, pp. 109-155.

Lawrence, P.R. and Lorsch, J.W. (1967), "Differentiation and integration in complex organizations", Administrative Science Quarterly, Vol. 12 No. 1, pp. 1-47.

Levina, N. and Vaast, E. (2005), "The emergence of boundary spanning competence in practice: Implications for implementation and use of information systems", MIS Quarterly, Vol. 29 No. 2, pp. 335-363.

Lewis, M.W. (2000), "Exploring paradox: Toward a more comprehensive guide", The Academy of Management Review, Vol. 25 No. 4, p. 760.

Mantere, S. and Ketokivi, M. (2013), "Reasoning in organization science", Academy of Management Review, Vol. 38 No. 1, pp. 70-89.

Marshall, C. and Rossman, G. (1995), Designing Qualitative Research, Sage Publications, Thousand Oaks, California.

Martini, A., Laugen, B.T., Gastaldi, L. and Corso, M. (2013), “Continuous innovation: Towards a paradoxical, ambidextrous combination of exploration and exploitation", International Journal of Technology Management, Vol. 61 No. 1, pp. 1-22.

Mintzberg, H. (1979), The Structuring of Organizations - A Synthesis of the Research, Prentice-Hall, New Jersey, USA.

Nonaka, I., Toyama, R. and Konno, N. (2000), "SECl, ba and leadership: A unified model of dynamic knowledge creation", Long Range Planning, Vol. 33 No. 1, pp. 5-34. 
O'Reilly, C.A. and Tushman, M.L. (2013), "Organizational ambidexterity: Past, present, and future", The Academy of Management Perspectives, Vol. 27 No. 4, pp. 324-338.

Okhuysen, G.A. and Bechky, B.A. (2009), "Coordination in organizations: An integrative perspective", The Academy of Management Annals, Vol. 3 No. 1, pp. 463-502.

Okhuysen, G.A. and Eisenhardt, K.M. (2002), "Integrating knowledge in groups: How formal interventions enable flexibility", Organization Science, Vol. 13 No. 4, pp. 370-386.

Raisch, S. (2008), "Balanced structures: Designing organizations for profitable growth", Long Range Planning, Vol. 41 No. 5, pp. 483-508.

Raisch, S., Birkinshaw, J., Probst, G. and Tushman, M.L. (2009), "Organizational ambidexterity: Balancing exploitation and exploration for sustained performance", Organization Science, Vol. 20 No. 4, pp. 685695.

Reich, B.H. and Benbasat, I. (2000), "Factors that influence the social dimension of alignment between business and information technology objectives", MIS Quarterly, Vol. 24 No. 1, p. 81.

Rothaermel, F.T. and Deeds, D.L. (2004), “Exploration and exploitation alliances in biotechnology: A system of new product development", Strategic Management Journal, Vol. 25 No. 3, pp. 201-221.

Rub, F. a. A. and Issa, A. a. (2012), "A business process modeling-based approach to investigate complex processes: Software development case study", Business Process Management Journal, Vol. 18 No. 1, pp. 122-137.

Shani, A.B.R., Coghlan, D. and Cirella, S. (2012), "Action research and collaborative management research: More than meets the eye?", International Journal of Action Research, Vol. 8 No. 1, pp. 45-67.

Sheremata, W. a. (2000), "Centrifugal and centripetal forces in radical new product development under time pressure", The Academy of Management Review, Vol. 25 No. 2, p. 389.

Smeds, R. (2003), "Simulation for accelerated learning and development in industrial management", Production Planning \& Control, Vol. 14 No. 2, pp. 107-110.

Smith, W.K. and Lewis, M.W. (2011), "Toward a Theory of Paradox: a Dynamic Equilibrium Model of Organizing.", Academy of Management Review, Vol. 36 No. 2, pp. 381-403.

Smith, W.K. and Tushman, M.L. (2005), "Managing strategic contradictions: A top management model for managing innovation streams", Organization Science, Vol. 16 No. 5, pp. 522-536.

Solaimani, S. and Bouwman, H. (2012), "A framework for the alignment of business model and business processes: A generic model for trans-sector innovation", Business Process Management Journal, Vol. 18 No. 4, pp. 655-679.

Stadler, C., Rajwani, T. and Karaba, F. (2014), "Solutions to the exploration/exploitation dilemma: Networks as a new level of analysis", International Journal of Management Reviews, Vol. 16 No. 2, pp. 172-193.

Stettner, U. and Lavie, D. (2013), "Ambidexterity under scrutiny: Exploration and exploitation via internal organization, alliances, and acquisitions", Strategic Management Journal, Vol. forthcomin. 
Swan, J., Newell, S., Scarbrough, H. and Hislop, D. (1999), "Knowledge management and innovation: Networks and networking", Journal of Knowledge Management, Vol. 3 No. 4, pp. 262-275.

Taylor-Cummings, A. (1998), "Bridging the user-IS gap: A study of major information systems projects", Journal of Information Technology, Vol. 13 No. 1, pp. 29-54.

Thompson, J. (1967), Organizations in Action, McGraw-Hill, USA.

Weick, K.E. (1995), Sensemaking in Organizations, Sage Publications, Thousand Oaks, California.

Weick, K.E. and Quinn, R.E. (1999), "Organizational change and development”, Annual Review of Psychology, Vol. 50, pp. 361-386.

Weick, K.E., Sutcliffe, K.M. and Obstfeld, D. (2005), "Organizing and the process of sensemaking", Organization Science, Vol. 16 No. 4, pp. 409-421.

Xu, P. (2009), "Coordination in large agile projects", Review of Business Information Systems, Vol. 13 No. 4, pp. 29-44.

Zollo, M. and Winter, S.G. (2002), "Deliberate learning and the evolution of dynamic capabilities", Organization Science, Vol. 13 No. 3, pp. 339-351. 
Developmental interventions using facilitated

business process modeling and simulation workshops

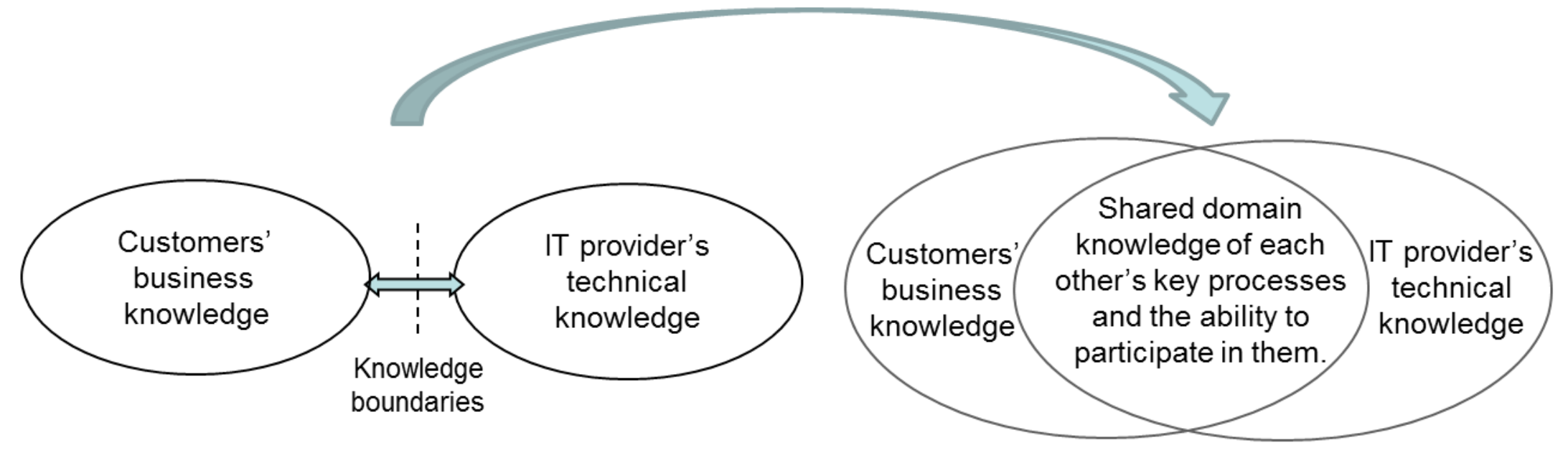

Figure 1. Crossing knowledge boundaries through developmental interventions towards shared domain knowledge. 
Double-bind relationships of ownership and customership.

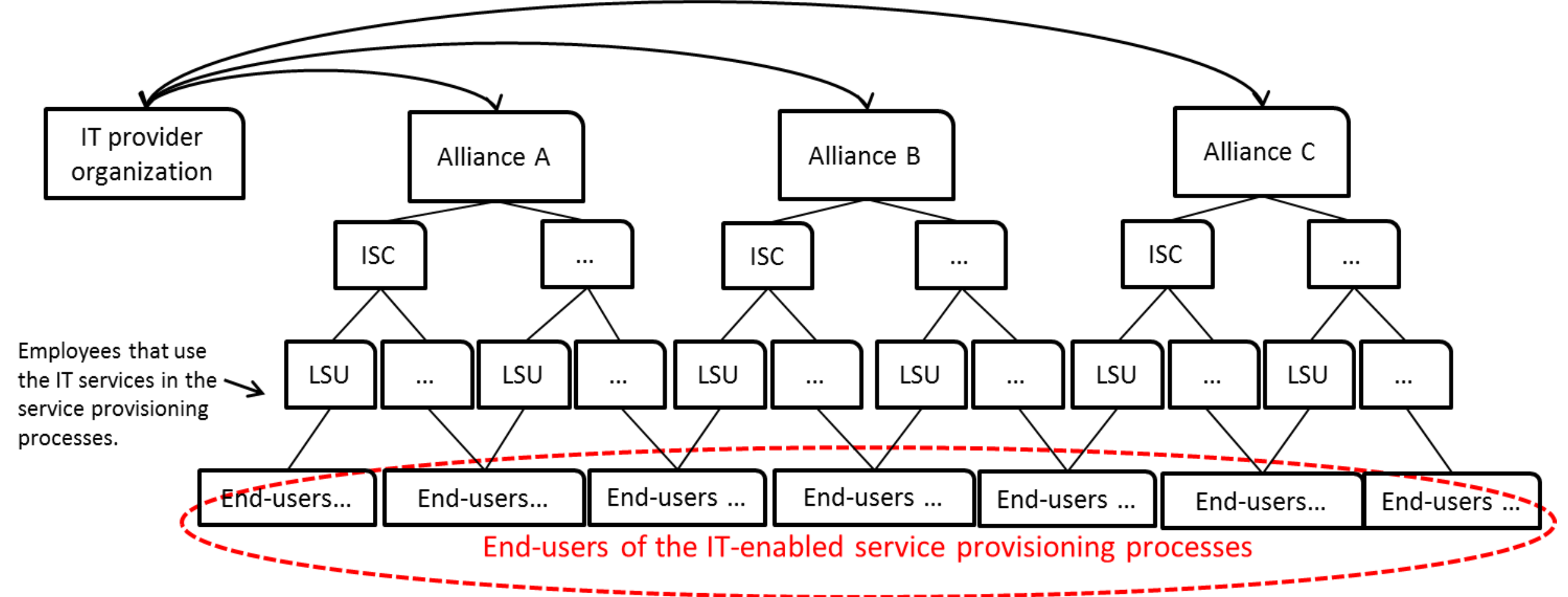

Figure 2. The studied organizations: The IT provider and its customer network. 
A process for building inter-organizational contextual ambidexterity into the IT-enabled service processes.

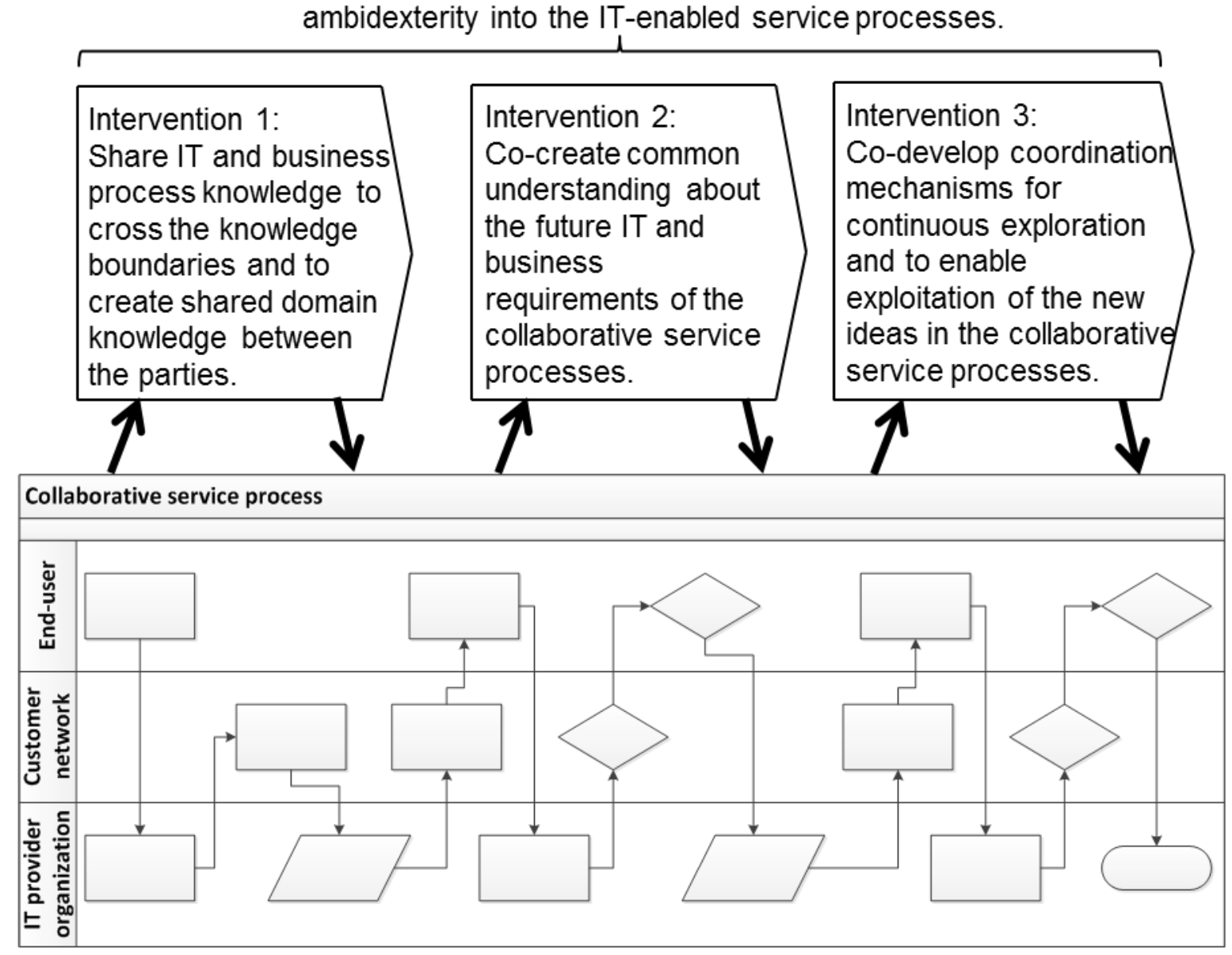

Figure 3. The three developmental interventions acted as a three-step process for building inter-organizational contextual ambidexterity into the IT-enabled service processes. 
Table 1. The business processes to be developed, the data collection points, and the parties involved in the consecutive developmental interventions.

\begin{tabular}{|c|c|c|c|}
\hline & $\begin{array}{l}\text { Developmental } \\
\text { intervention } 1 \\
\text { in fall } 2006\end{array}$ & $\begin{array}{c}\text { Developmental } \\
\text { intervention } 2 \\
\text { in spring } 2007\end{array}$ & $\begin{array}{c}\text { Developmental } \\
\text { intervention } 3 \\
\text { in fall } 2007\end{array}$ \\
\hline $\begin{array}{l}\text { Business process } \\
\text { to be developed }\end{array}$ & $\begin{array}{l}\text { End-users' contact } \\
\text { processing process in current } \\
\text { and in ideal state (from the } \\
\text { perspectives of customer } \\
\text { groups A and B) }\end{array}$ & $\begin{array}{l}\text { End-users' procurement } \\
\text { process (from the perspectives } \\
\text { of customer groups } A \text { and } B \\
\text { and two partner } \\
\text { organizations) }\end{array}$ & $\begin{array}{l}\text { End-users' daily business } \\
\text { processes (from the } \\
\text { perspectives of customer } \\
\text { groups } A, B \text {, and } C \text { ) }\end{array}$ \\
\hline $\begin{array}{l}\text { Process } \\
\text { modeling } \\
\text { workshops }\end{array}$ & $\begin{array}{ll}\text { - } & \text { weeks } 35-37 \\
\text { - } & 18 \text { customer } \\
& \text { representatives and } 2 \text { IT } \\
& \text { provider representatives } \\
\text { - } & 5 \text { workshops } \\
\end{array}$ & $\begin{array}{ll}- & \text { weeks } 4-10 \\
\text { - } & 11 \text { customer } \\
& \text { representatives } \\
\text { - } & 5 \text { workshops } \\
\end{array}$ & $\begin{array}{l}\text { - } \quad \text { weeks } 39-40 \\
\text { - } 9 \text { customer } \\
\text { representatives and } 7 I T \\
\text { provider representatives } \\
\text { - } 2 \text { workshops } \\
\end{array}$ \\
\hline Interviews & $\begin{array}{l}\text { - } 21.8 .2006 \text { and } 20.9 .2006 \\
\text { - } 9 \text { IT provider } \\
\text { representatives } \\
\text { - } 8 \text { interviews }\end{array}$ & $\begin{array}{ll}\text { - } & \text { weeks } 4-10 \\
\text { - } & 2 \text { customer } \\
& \text { representatives, } 1 \text { IT } \\
\text { provider representative, } \\
\text { and } 1 \text { partner organization } \\
\text { representative } \\
\text { - } 4 \text { interviews }\end{array}$ & $\begin{array}{l}\text { - } \quad \text { Weeks } 39-40 \\
\text { - } 5 \text { IT provider } \\
\text { representatives } \\
\text { - } 3 \text { interviews }\end{array}$ \\
\hline $\begin{array}{l}\text { Simulation } \\
\text { workshops }\end{array}$ & $\begin{array}{ll}\text { - } & 5.10 .2006 \\
\text { - } & 16 \text { customer } \\
\text { representatives and } 13 \\
I T \text { provider } \\
\text { representatives }\end{array}$ & $\begin{array}{ll}- & 28.3 .2007 \\
- & 10 \text { customer } \\
& \text { representatives, } 2 \text { IT } \\
\text { provider representatives, } \\
\text { and } 5 \text { partner organization } \\
\text { representatives }\end{array}$ & $\begin{array}{ll}- & 1.11 .2007 \\
- & 18 \text { customer } \\
& \text { representatives and } 7 \text { IT } \\
& \text { provider representatives }\end{array}$ \\
\hline Archival data & $\begin{array}{l}\text { - IT provider's service } \\
\text { descriptions } \\
\text { - IT provider's annual } \\
\text { report } \\
\text { - Customers' annual } \\
\text { report }\end{array}$ & $\begin{array}{l}\text { - IT provider's requirements } \\
\text { specification document for } \\
\text { the IT system } \\
\text { - IT provider's IT system } \\
\text { development and } \\
\text { customer needs reports } \\
\text { - } \begin{array}{l}\text { Presentations on the IT } \\
\text { system's structure }\end{array}\end{array}$ & $\begin{array}{l}\text { - IT provider's process } \\
\text { models on the IT system } \\
\text { - Customers' process } \\
\text { documents }\end{array}$ \\
\hline
\end{tabular}




\section{Acknowledgments:}

The research reported in this paper has been conducted in Madeleine and CoCoNet research projects at the Enterprise Simulation Laboratory SimLab, Department of Industrial Engineering and Management, Aalto University School of Science, Finland. Earlier results have been published in Lavikka's (2010) Llicentiate's thesis published in the Dissertation Series of Aalto University School of Science and in the conference paper Lavikka, R., Jaatinen, M. \& Smeds, R. (2008) Business process requirements elicitation through process modeling and simulation. Proceedings of the APMS 2008 International Conference on Advances in Production Management Systems, Innovations in Networks, IFIP, Sept. 14-17, 2008, Espoo, Finland, pp. 349-358.

The Academy of Finland and the Finnish Funding Agency for Technology and Innovation Tekes with partner companies have financially supported the research, which is gratefully acknowledged. In addition, we thank the guest editor, Doctor Antonella Martini and two anonymous reviewers.

\section{Biographical Details:}

[Author 1 bio] Rita Lavikka, Lic.Sc.(Tech.), is a doctoral candidate at the Department of Industrial Engineering and Management, Aalto University School of Science, Finland. At the moment, she is writing her dissertation on Co-creation of coordination in inter-organizational business processes. In addition, she is a lecturer at the university's master and doctoral level course on Networked Business Processes and Models. She has co-authored articles published in international journals of Production Planning and Control and Corporate Communications.

[Author 2 bio] Riitta Smeds, D.Sc.(Tech.) is Professor of Business and Service Processes in Digital Networks and Director of the SimLab Business Process Simulation Laboratory at the Department of Industrial Engineering and Management, Aalto University School of Science, Finland. Her research focuses on the management of innovation in service networks, inter-organizational knowledge co-creation and collaborative innovation methods. She is chair of the IFIP WG 5.7 Special Interest Group on Interactive Learning in Industrial Management, and Adjunct Professor at Hanken School of Economics.

[Author 3 bio] Miia Jaatinen, docent, D.Soc.Sc, is teaching research scientist at the department of Industrial Engineering and Management, Aalto University School of Science, Finland. She received a doctoral degree in communication from the University of Helsinki. She is also adjunct professor in Public Relations and Organizational Communication at the University of Jyväskylä. She has taught university courses on communication, management, and development in business networks. Her research interests focus on inter-organizational communication and knowledge co-creation. 